\title{
Design of serially connected district heating heat pumps utilising a geothermal heat source
}

\author{
Jensen, Jonas Kjær; Ommen, Torben Schmidt; Markussen, Wiebke Brix; Elmegaard, Brian
}

Published in:

Energy

Link to article, DOI:

10.1016/j.energy.2017.03.164

Publication date:

2017

Document Version

Peer reviewed version

Link back to DTU Orbit

Citation (APA):

Jensen, J. K., Ommen, T. S., Markussen, W. B., \& Elmegaard, B. (2017). Design of serially connected district heating heat pumps utilising a geothermal heat source. Energy, 137, 865-877.

https://doi.org/10.1016/j.energy.2017.03.164

\section{General rights}

Copyright and moral rights for the publications made accessible in the public portal are retained by the authors and/or other copyright owners and it is a condition of accessing publications that users recognise and abide by the legal requirements associated with these rights.

- Users may download and print one copy of any publication from the public portal for the purpose of private study or research.

- You may not further distribute the material or use it for any profit-making activity or commercial gain

- You may freely distribute the URL identifying the publication in the public portal 


\title{
Design of serially connected district heating heat pumps utilising a geothermal heat source
}

\author{
Jonas K. Jensen ${ }^{\mathrm{a}, *}$, Torben Ommen ${ }^{\mathrm{a}}$, Wiebke B. Markussen ${ }^{\mathrm{a}}$, Brian Elmegaard ${ }^{\mathrm{a}}$ \\ ${ }^{a}$ Technical University of Denmark, Department of Mechanical Engineering, Nils Koppels Alle, Building 403, DK - 2800, Kgs. Lyngby, Denmark
}

\begin{abstract}
The design of two heat pumps (HP), connected in series, was investigated for operation in the district heating (DH) network of the Greater Copenhagen area, Denmark. The installation was dimensioned to supply $7.2 \mathrm{MW}$ of heat at a temperature of $85{ }^{\circ} \mathrm{C}$. The heat pumps utilise a geothermal heat source at $73{ }^{\circ} \mathrm{C}$. Both heat source and sink experience a large temperature change, which may lead to decreased performance for single vapour compression HP. The performance may be increased by using HPs connected in series and by applying HPs with zeotropic mixtures. First a generic study with a simple representation of the HP was applied to investigate optimal system configurations. It was shown that using two heat pumps in series with direct heat exchange in parallel with the first heat pump could increase the performance compared to the HP performance. Detailed thermodynamic models of a zeotropic mixture HP predicted that an exergetic efficiency of the units between $50 \%$ and $65 \%$ is possible. The technical feasibility as well as the economic viability of this installation was investigated for a range of optimal configurations. The analysis recommends a heat pump configuration with a system exergetic efficiency of $63 \%$.
\end{abstract}

Keywords: District heating, Geothermal, Hybrid heat pump, Absorption-compression heat pump, compression re-sorption heat pump

\section{Introduction}

The municipality of Copenhagen, together with the Greater Copenhagen Area in Denmark, has the target to supply CO2 neutral district heating (DH) in 2025 [1]. The proposed method for achieving this target is mainly based on the conversion from fossil fuels to biomass in the large central combined heat and power (CHP) plants as well as incineration of waste in smaller CHP units. Waste incineration contributes as base load technology today and is expected to continue in the years to come, although a slight decrease in available resources is projected [2]. Focussing mainly on biomass as the sole fuel for intermittent and peak demand presents a significant risk in terms of security of supply [3]. Other supply technologies, such as heat pumps (HPs) utilising geothermal heat sources, or heat sources close to ambient, are also considered [4]. It is expected that approximately $300 \mathrm{MW}$ heat production capacity from HP technologies is economically feasible [2], if appropriate heat sources can be located in the proximity of the DH network [5].

Geothermal heat sources are used for a wide range of applications including both direct and indirect utilisation in district heating networks [6]. In many areas (e.g. in Turkey), the obtained temperatures of the production wells exceed or matches the supply temperatures of the DH network [7]. The heat cost from geothermal installations are affected by many factors (such as investment cost for wells and HP, running cost for pumps and HP etc. [8]) which results in highly different profitability even for adjacent distribution areas [9]. Further, the choice of HP technology e.g. refrigerant may also impose a significant change in the cost of supplied heat [10]. For utilisation in Danish DH systems, the temperature requirements for direct utilisation limits the possibilities and economic applicability [11].

\footnotetext{
${ }^{*}$ Corresponding author

Email addresses: jkj je@mek.dtu.dk (Jonas K. Jensen), tsom@mek.dtu.dk (Torben Ommen), wb@mek.dtu.dk (Wiebke B. Markussen), be@mek.dtu.dk (Brian Elmegaard)
} 


\begin{tabular}{ll} 
Nomenclature & \\
Abbreviations & \\
COP Coefficient of Performance & Greek letters \\
DH District heating & $\Delta$ Difference \\
EES Engineering Equation Solver & $\varepsilon$ Exergetic efficiency \\
GT Geothermal stream & $\epsilon$ Heat exchanger effectiveness \\
HACHP Hybrid absorption compression heat pump & $\eta$ Efficiency \\
HEX Heat Exchanger & Subscripts \\
VCHP Vapour compression heat pump & 0 Dead state \\
NPV Net present value & DH District heating stream \\
PV Present value & GT Geothermal stream \\
TCI Total capital investment & $H$ High \\
$S y m b o l s$ & HP Heat pump \\
$c_{p}$ Specific heat capacity $(\mathrm{kJ} / \mathrm{kg}-\mathrm{K})$ & HX Heat exchanger \\
$\dot{E}$ Exergy rate $(\mathrm{kW})$ & in Inlet \\
$f$ Ratio $($ dimensionless $)$ & is Isentropic \\
$\dot{m}$ Mass flow rate $(\mathrm{kg} / \mathrm{s})$ & IH Internal heat exchanger \\
$p$ Pressure $($ bar $)$ & $m$ Mass flow ratio \\
$\dot{Q}$ Heat rate $(\mathrm{kW})$ & MX Mixer \\
$T$ Temperature $\left({ }^{\circ} \mathrm{C}(\right.$ difference K)) & out Outlet \\
$\bar{T}$ Mean temperature $\left({ }^{\circ} \mathrm{C}(\right.$ difference K)) & pp Pinch point \\
$\dot{W}$ Power $(\mathrm{kW})$ & $Q$ Heat load ratio \\
$x$ Amonia mass fraction $(\mathrm{kg} / \mathrm{kg})$ & tot Total \\
\hline
\end{tabular}

However, by use of a geothermal heat source at a lower temperature than for direct utilisation, the temperature lift of the required HP is limited and may result in a favourable overall cost of heat.. It may thus be a relevant alternative to biomass, but the technology is limited by drawbacks, such as a rather inflexible load profile due to the limitations of utilising the well, as well as the requirement for large investments to set up such systems.

For applications in $\mathrm{DH}$, the temperature variation of either source or sink stream is typically of a magnitude, where serial connection of HPs, may provide an increase in the coefficient of performance (COP) [12]. On the other hand, the economy of scale may suggest that the investment of a single unit is less than for two smaller units, when considering an equal total heat load. The most profitable solution may further vary with HP parameters such as sink temperature, temperature lift and temperature variation of sink and source streams.

An alternative approach to increasing the COP of HPs working between sink and source streams with high temperature variations is the application of the hybrid absorption compression heat pump (HACHP). The HACHP is a practical implementation of the Osenbrück cycle [13]. The Osenbrück cycle seeks to approach the Lorenz cycle [14] and thus seeks to minimize the irreversbilites related to the heat transfer with the sink and source by adjusting the temperature variation of the working fluid to match these [15]. In practice this is achieved by the application of a zeotropic working fluid, typically ammonia-water, resulting in a non-isothermal phase-change of the working fluid. Hultén \& Berntsson [16] shows that the HACHP increases the performance by up to $10 \%$ compared to a VCHP when the sink and source glides are $20 \mathrm{~K}$, however the performance was reduced by $10 \%$ at a sink and source glide of $5 \mathrm{~K}$. Hultén \& Berntsson later showed that increasing pressure limits would allow an increase in the COP of HACHP [17]. A further advantage of using a zeotropic working fluid is the reduction of vapour pressure compared to the vapour pressure of the pure volatile component [18]. The reduction of vapour pressure is an advantage for high temperature applications, such as district heating, as it allows the utilisation of low pressure component for high temperature applications [18]. With the current pressure level of commercially available components the HACHP is capable of delivering significantly higher temperatures than the conventional vapour compression heat pump (VCHP), however this requires the correct combination of ammonia mass fraction and circulation ratio to be identified [19]. The HACHP has 
been shown to provide a good return on investment as well as a significant reduction of $\mathrm{CO}_{2}$ emission when applied for industrial process heating, in e.g spray drying facilities [20].

Detailed thermodynamic and economic models of various single stage VCHP and HACHP were developed and investigated in Ommen et al. [21] and Jensen et al. [22]. The results show, that the best available technology in terms of net present value (NPV), typically depends on the performance and investment of the HP systems at the specific layout of the sink/source process streams. Besides the thermodynamic performance of the cycle and working fluid, it is important to consider the application limits of the individual components.

Possible benefits of integrating several HPs in series are presented by Ommen et al. [23]. The analysis is performed for VCHPs using economic scenarios relevant for industrial integration/application. For such a case, the increased performance does not economically compensate for the increase in investment at the expected technical lifetime of the plant.

In the case of utility production in Denmark, a different taxation scheme applies to the utilised electricity. Electricity for industrial process heat is exempt from taxation while full taxation is applied in the case of utility production, such as DH. The increased heat production cost for utilities, changes the economic optimum for a HP installation towards systems with lower running costs (higher COP) at expense of increased capital investment. In this way, the performance benefit of HPs operated in series becomes viable. To obtain low heat production prices, the utility companies are required to select utility plants with low consumer cost, where fuel (e.g. electricity) cost, market price of co-produced utilities (if any), O\&M, taxes as well as investments are included in the calculation. An example of this difference between the two economic scenarios is presented in Fig. 1 for VCHPs [24].

It is shown, that the benefit of a serial connection depends mainly on the economic case and the temperature difference of the HP sink and source streams. All other relevant economic parameters are similar to those presented in [23]. For the case of DH, it is shown that serial connection of two HPs is preferable for both of the presented sink and source temperature differences. At low source temperature difference, the benefit of serial connection is reduced to an insignificant increase considering the uncertainties of the analysis. At sink and source temperature differences of $20 \mathrm{~K}$, the economic benefit exceeds $5 \%$.

In case the temperature of the heat source is higher than the DH return, the system allows direct heat exchange (HEX) with the DH stream [25], which is preferable in terms of both cost and efficiency. After utilising the possibility of direct HEX, the temperature differences for the present geothermal installation exceed $20 \mathrm{~K}$ for both sink and source (approximately $30 \mathrm{~K}$ for both). For such high sink and source temperature differences, the analysis indicates, that the proposed setup (with VCHPs) should utilise two (or possibly three) HPs in series.

A simplified example of integrating two generic HPs in series with a geothermal heat source is presented in Fig. 2. For integration of heat pumps in serial configuration, the counter-current configuration is preferable in terms of both energetic performance and technical constraints [23]. An example of a possible temperature - heat load diagram is presented in Fig. 3. The units are grouped by their integration with the heat sink. The flow of the sink stream exiting HP 1 and the stream exiting the direct HEX are mixed before being heated to the final specifications by HP 2 .

The analysis of the present study focusses on the possible increase in performance from the use of HP units operated in series alongside the utilisation of direct heat exchange with the heat source. Specifically, the performance improvements of both generic HP units and specific HACHPs are analysed and evaluated. The HACHP presents an interesting case, as the cycle configuration can be optimised for low exergy destruction from heat exchange, compared to the isothermal vapour compression HPs. At the same time, the benefit from serial connection is closely related to the minimisation of exergy destruction from heat exchange, which implies that the possible benefit from operation in series may be lower for this type of HP. The performance of the serially connected HACHPs is further investigated in terms of the plant economy.

The analysis follows a three step increase in the level of detail of the performance evaluation. As an initial investigation, basic assumptions regarding the exergetic efficiency of the individual unit are applied to understand the influence of design parameters on the system exergetic efficiency. Then a detailed thermodynamic model of the HACHP is used to predict the performance of the total installation. Finally, the technical and economic considerations are analysed to determine the best possible integration of two HACHPs in a range of exergy-optimal configurations. 


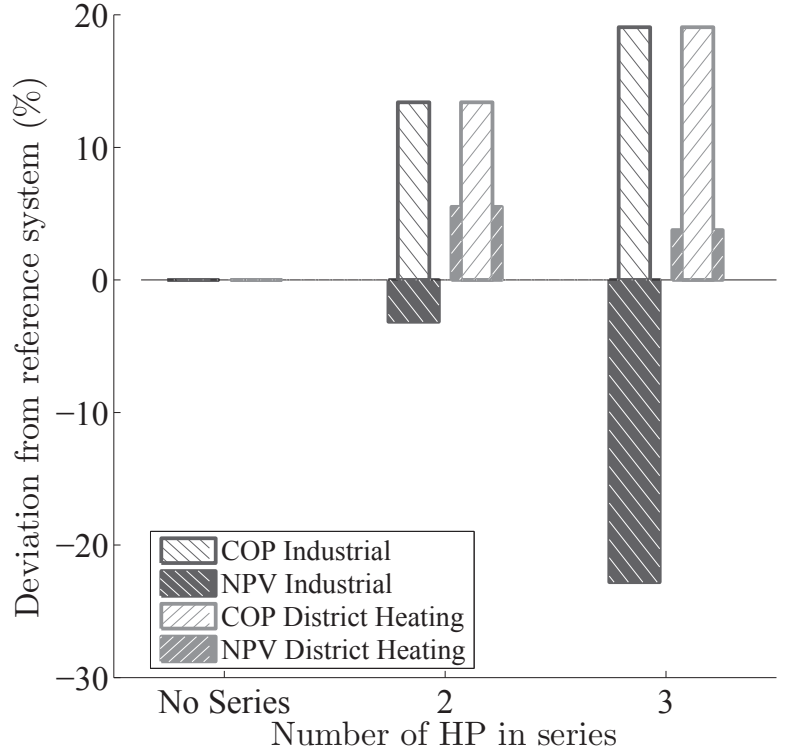

(a)

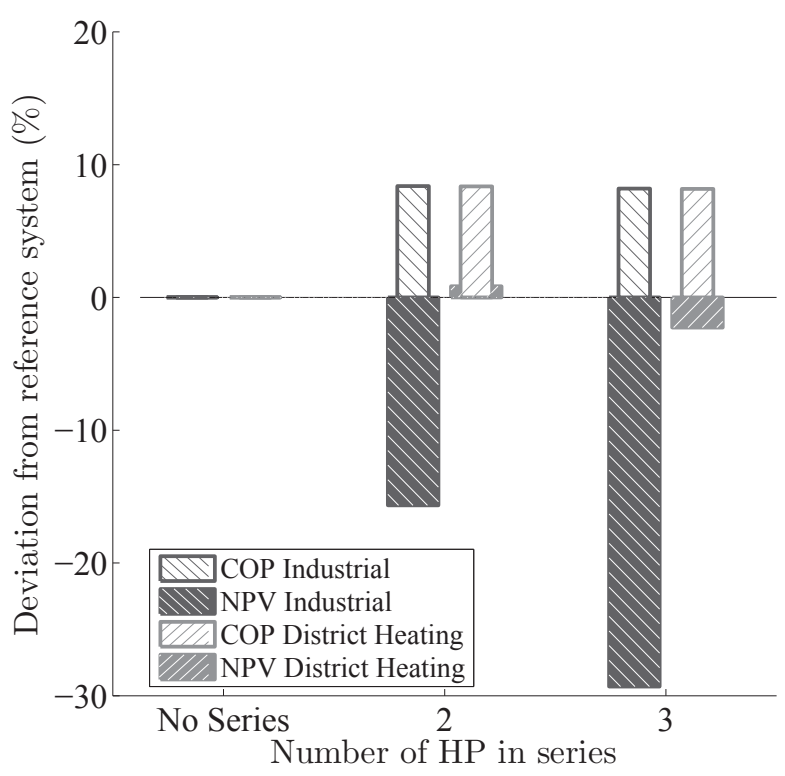

(b)

Figure 1: Example of different economic performances of the number of HPs in series for two relevant cases in Danish energy system. The benefit of serial connection depends mainly on the economic case and the temperature difference of HP sink and source streams. (a) Serially connected HPs with overall sink temperature difference at $20 \mathrm{~K}$ and source temperature difference at $20 \mathrm{~K}$. (b) Serially connected HPs with overall sink temperature difference at $40 \mathrm{~K}$ and source temperature difference at $10 \mathrm{~K}[24]$.

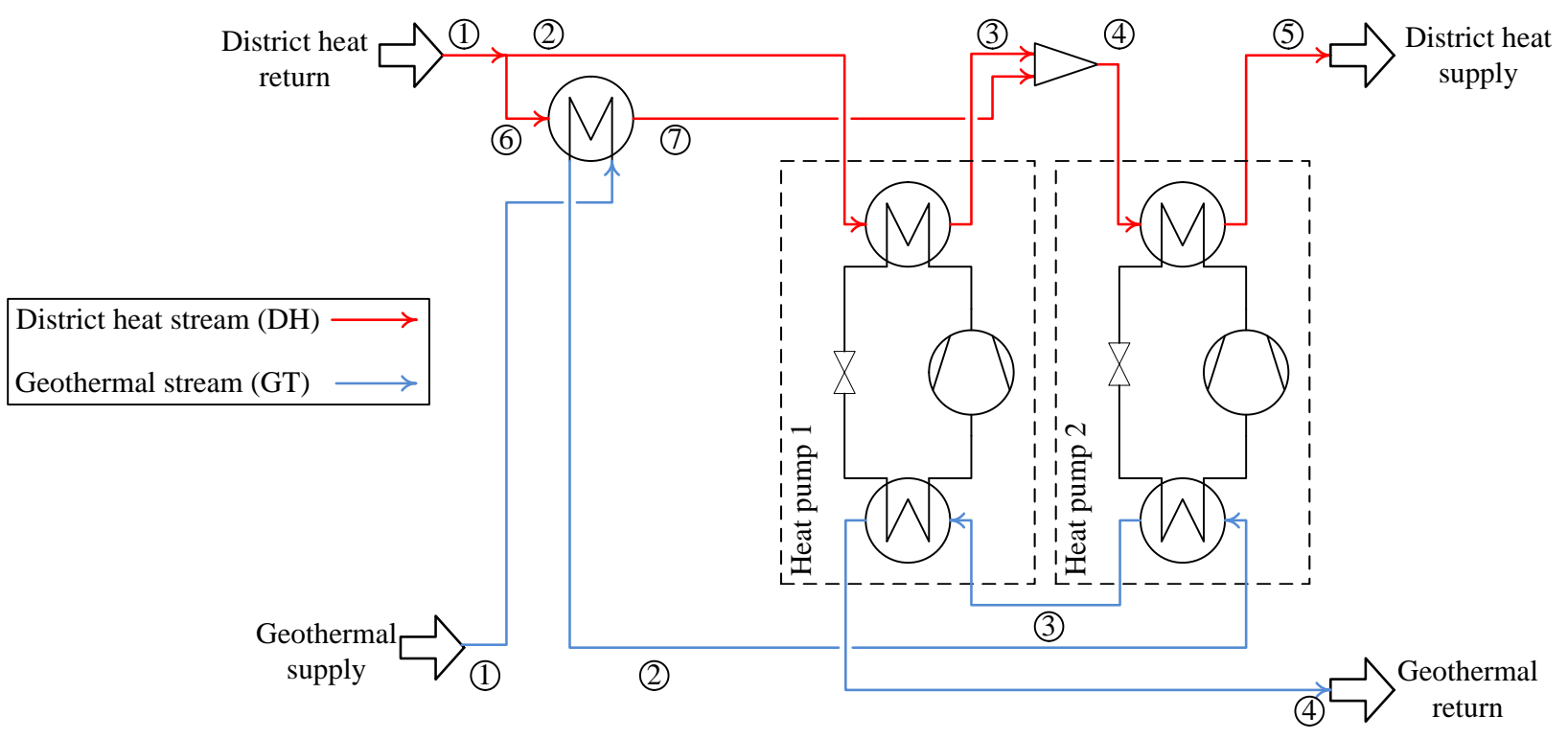

Figure 2: Counter-current installation of two heat pumps 


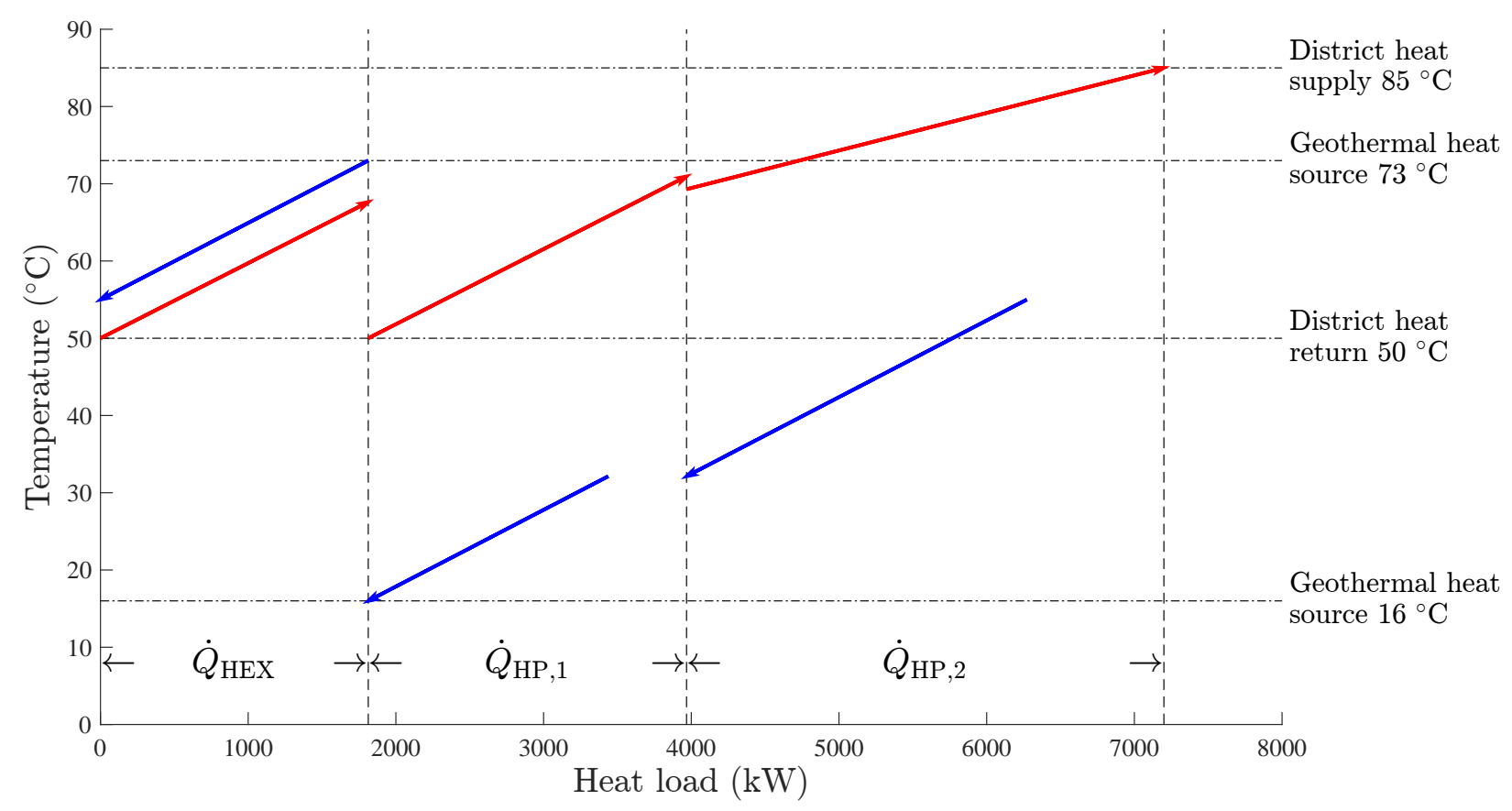

Figure 3: Principle temperature - heat load diagram of counter-current configuration

\section{Method}

\subsection{Case description}

The design criteria for the geothermal heat pump installation are stated in Table 1. Here both the key economic parameters such as assumed lifetime, yearly operation hours etc. are stated along with the dimensioning temperature levels and heat loads.

The system is designed to supply at total heat load of $\dot{Q}_{\mathrm{DH}}=7.2 \mathrm{MW}$ to the district heating network. As direct heat exchange is imposed, the HPs will not deliver all 7.2 MW but only the remaining load, as seen in Eq. (1).

$$
\dot{Q}_{\mathrm{HP}, \mathrm{tot}}=\dot{Q}_{\mathrm{DH}}-\dot{Q}_{\mathrm{HEX}}
$$

The two heat pumps share the remaining load such that: $\dot{Q}_{\mathrm{HP}, \text { tot }}=\dot{Q}_{\mathrm{HP}, 1}+\dot{Q}_{\mathrm{HP}, 2}$. A HP heat load ratio, $f_{Q}$, was applied to determine the load share between the two heat pumps. The HP heat load ratio was defined as seen in Eq. (2).

$$
f_{Q}=\frac{\dot{Q}_{\mathrm{HP}, 1}}{\dot{Q}_{\mathrm{HP}, \text { tot }}}
$$

Hence, if $f_{Q}=0$ all HP heat load will be supplied by heat pump 2 while all HP heat load will be supplied by heat pump 1 if $f_{Q}=1$.

As seen in Fig. 2 the district heating return stream is split before being heated by the HEX and HP 1, respectively. The mass flow ratio, $f_{m}$, was defined as the ratio between the mass flow supplied to HP $1, \dot{m}_{\mathrm{DH}, 2}$ and the total district heating mass flow rate, $\dot{m}_{\mathrm{DH}, 1}$, as seen in Eq. (3).

$$
f_{m}=\frac{\dot{m}_{\mathrm{DH}, 2}}{\dot{m}_{\mathrm{DH}, 1}}
$$

Hence, if $f_{m}=0 \mathrm{HP} 1$ is bypassed and all mass flow is supplied to the HEX. Conversely, if $f_{m}=1$, the HEX is bypassed and all mass flow is sent to HP 2 .

The values of $f_{Q}$ and $f_{m}$ were to be determined in the design procedure. $f_{Q}$ and $f_{m}$ were determined to minimize the overall cost of the system, the Present Value (PV), under the constraints of commercially available components. 
Table 1: Design criteria for the geothermal district heating plant

\begin{tabular}{llll}
\hline \multicolumn{2}{c}{ Basis for economic evaluation } & \multicolumn{2}{c}{ Design temperature and heat loads } \\
\hline Lifetime & 20 years & $T_{\mathrm{DH}, \text { supply }}=T_{\mathrm{DH}, 5}$ & $85^{\circ} \mathrm{C}$ \\
Yearly operating hours & 3500 hours & $T_{\mathrm{DH}, \text { return }}=T_{\mathrm{DH}, 1}$ & $50{ }^{\circ} \mathrm{C}$ \\
Interest rate & $4.5 \%$ & $T_{\mathrm{GT}, \text { supply }}=T_{\mathrm{GT}, 1}$ & $73{ }^{\circ} \mathrm{C}$ \\
Inflation rate & $1.9 \%$ & $T_{\mathrm{GT}, \text { return }}=T_{\mathrm{GT}, 4}$ & $16{ }^{\circ} \mathrm{C}$ \\
Electricity cost & $0.179 \mathrm{EUR} / \mathrm{kWh}$ & $\dot{Q}_{\mathrm{DH}}$ & $7.2 \mathrm{MW}$ \\
\hline
\end{tabular}

\subsection{Generic energy and exergy model of the geothermal installation}

To determine the thermodynamic advantages of utilizing two heat pumps in series together with the direct heat exchange, a generic energy and exergy model of the installation was constructed. Using this model the thermodynamic optimum values of, $f_{Q}$ and $f_{m}$ were investigated. As described in section 2.1 a true serial connection only exists for $0<f_{Q}<1$, as only one HP is applied for $f_{Q}=0$ and $f_{Q}=1$. Further, the direct HEX is only applied for $f_{m}<1$, as the HEX is bypassed for $f_{m}=1$. Hence, if both optimal values are found to be between zero and unity for $f_{Q}$ and lesser than unity for $f_{m}$ it can be concluded that the configuration, shown in Fig. 2, utilising both serial connected HPs and direct heat exchange is thermodynamically advantageous.

Further, using this model it was investigated how the optimal values of $f_{Q}$ and $f_{m}$ were affected by the exergetic efficiency of the individual heat pumps and the pinch point temperature difference of the HEX.

To construct the model it was assumed that the specific heat capacity, $c_{p}$, was constant and equal for both the district heating and geothermal stream, the value of $c_{p}$ was evaluated for pure water at the average temperature in the system, $\bar{T}=\frac{1}{2}\left(T_{\mathrm{DH} \text {,supply }}+T_{\mathrm{GT} \text {,return }}\right)$. Pressure losses were neglected and the pressure of both the district heating stream and the geothermal stream was assumed to be 5 bar.

For the exergy analysis the dead state temperature was assumed to be $T_{0}=16{ }^{\circ} \mathrm{C}$. Hence, all streams depicted in Fig. 3 occur above the dead state temperature. As this was the case: all heated streams were allocated as product streams while all cooled streams were considered as fuel streams.

As pressure losses were neglected the rate of change in physical exergy over a heated stream was calculated based on the inlet and outlet temperatures and the streams capacity rate $\left(\dot{m} c_{p}\right)$, as seen in Eq. (4). A similar approach was applied to cooled streams, as seen in Eq. (5).

$$
\begin{gathered}
\Delta \dot{E}_{\text {Heated }}=\dot{m} c_{p}\left(T_{\text {out }}-T_{\text {in }}\right)-T_{0} \dot{m} c_{p} \ln \left(\frac{T_{\text {out }}}{T_{\text {in }}}\right) \\
\Delta \dot{E}_{\text {Cooled }}=\dot{m} c_{p}\left(T_{\text {in }}-T_{\text {out }}\right)-T_{0} \dot{m} c_{p} \ln \left(\frac{T_{\text {in }}}{T_{\text {out }}}\right)
\end{gathered}
$$

The exergetic efficiency of components or systems was calculated as the of ratio of the relevant exergetic product to the relevant exergetic fuel, as seen Eq. (6).

$$
\varepsilon=\frac{\dot{E}_{\text {product }}}{\dot{E}_{\text {fuel }}}
$$

The direct heat exchange HEX was modelled as a counter flow heat exchanger, as seen in Figs. 2 and 3 . The heat load of the HEX was determined by the pinch point temperature difference, $\Delta T_{\mathrm{pp}, \mathrm{HEX}}$, defined as the minimum temperature difference in the HEX. As the HEX operates without phase change, $\Delta T_{\mathrm{pp}, \mathrm{HEX}}$ can be determined as seen in Eq. (7).

$$
\Delta T_{\mathrm{pp}, \mathrm{HEX}}=\min \left(T_{\mathrm{GT}, 2}-T_{\mathrm{DH}, 2} ; T_{\mathrm{GT}, 1}-T_{\mathrm{DH}, 7}\right)
$$

The heat load was subsequently determined from Eq. (8).

$$
\dot{Q}_{\mathrm{HEX}}=\dot{m}_{\mathrm{DH}, 6} c_{p}\left(T_{\mathrm{DH}, 7}-T_{\mathrm{DH}, 6}\right)=\dot{m}_{\mathrm{GT}, 1} c_{p}\left(T_{\mathrm{GT}, 1}-T_{\mathrm{GT}, 2}\right)
$$


The exergetic efficiency of the HEX was found using Eqs. (4) - (6). The exergetic product of the HEX was the heat supplied to the DH stream and thus the exergetic product can be found using Eq. (4). The exergetic fuel was the heat supplied from the GT stream and was thus calculated using Eq. (5). The resulting exergetic efficiency of the HEX can be seen in Eq. (9).

$$
\varepsilon_{\mathrm{HEX}}=\frac{\dot{m}_{\mathrm{DH}, 6}}{\dot{m}_{\mathrm{GT}, 1}} \frac{\left(T_{\mathrm{DH}, 7}-T_{\mathrm{DH}, 6}\right)-T_{0} \ln \left(\frac{T_{\mathrm{DH}, 7}}{T_{\mathrm{DH}, 6}}\right)}{\left(T_{\mathrm{GT}, 1}-T_{\mathrm{GT}, 2}\right)-T_{0} \ln \left(\frac{T_{\mathrm{GT}, 1}}{T_{\mathrm{GT}, 2}}\right)}
$$

Both HPs in the system were treated as generic HPs with a given exergetic efficiency, $\varepsilon_{\mathrm{HP}}$. The COP of the heat pumps were determined from the given HP exergetic efficiency and the operating conditions (DH and GT temperatures). For the analysis of the heat pumps, the DH stream was termed the heat sink while the GT stream was termed the heat source.

The exergetic product of the HP was assumed to be the heat supplied to the DH stream while the exergetic fuel was the sum of the heat supplied from the GT stream and the supplied work, $\dot{W}_{\mathrm{HP}}$. Hence, the exergetic efficiency of the HP was determined as seen in Eq. (10).

$$
\varepsilon_{\mathrm{HP}}=\frac{\dot{m}_{\mathrm{DH}} c_{p}\left(T_{\mathrm{DH}, \text { out }}-T_{\mathrm{DH}, \mathrm{in}}\right)-T_{0} \dot{m}_{\mathrm{DH}} c_{p} \ln \left(\frac{T_{\mathrm{DH}, \text { out }}}{T_{\mathrm{DH}, \text { in }}}\right)}{\dot{m}_{\mathrm{GT}} c_{p}\left(T_{\mathrm{GT}, \text { in }}-T_{\mathrm{GT}, \text { out }}\right)-T_{0} \dot{m}_{\mathrm{GT}} c_{p} \ln \left(\frac{T_{\mathrm{GT}, \text { in }}}{T_{\mathrm{GT}, \text { out }}}\right)+\dot{W}_{\mathrm{HP}}}
$$

By applying the definitions of the sink and source heat loads, $\dot{Q}_{\text {sink }}$ and $\dot{Q}_{\text {source }}$, Eqs. (11) \& (12), as well as the definition of a logarithmic mean sink and source temperature, $\bar{T}_{\text {sink }}$ and $\bar{T}_{\text {source }}$, Eq. (13), the HP exergetic efficiency was reduced to the expression presented in Eq. (14).

$$
\begin{aligned}
& \dot{Q}_{\text {sink }}=\dot{m}_{\mathrm{DH}} c_{p}\left(T_{\mathrm{DH}, \text { out }}-T_{\mathrm{DH}, \text { in }}\right) \\
& \dot{Q}_{\text {source }}=\dot{m}_{\mathrm{GT}} c_{p}\left(T_{\mathrm{GT}, \text { in }}-T_{\mathrm{GT}, \text { out }}\right) \\
& \bar{T}_{\text {sink }}=\frac{T_{\mathrm{DH}, \text { out }}-T_{\mathrm{DH}, \text { in }}}{\ln \left(\frac{T_{\mathrm{DH}, \text { out }}}{T_{\mathrm{DH}, \text { in }}}\right)}, \quad \bar{T}_{\text {source }}=\frac{T_{\mathrm{GT}, \text { in }}-T_{\mathrm{GT}, \text { out }}}{\ln \left(\frac{T_{\mathrm{GT}, \text { in }}}{T_{\mathrm{GT}, \text { out }}}\right)} \\
& \varepsilon_{\mathrm{HP}}=\frac{1-\frac{T_{0}}{\bar{T}_{\text {sink }}}}{1-\frac{\dot{Q}_{\text {source }}}{\dot{Q}_{\text {sink }}} \frac{T_{0}}{\bar{T}_{\text {source }}}}
\end{aligned}
$$

The COP of the HPs was defined as the ratio between the useful heat output $\dot{Q}_{\text {sink }}$ and work input $\dot{W}_{\text {HP }}$, as seen in Eq. (15). Neglecting heat losses and assuming a steady state energy balance over the HP, allows the work input to be described as the difference between the sink and source heat load.

$$
\mathrm{COP}=\frac{\dot{Q}_{\text {sink }}}{\dot{W}_{\mathrm{HP}}}=\frac{\dot{Q}_{\text {sink }}}{\dot{Q}_{\text {sink }}-\dot{Q}_{\text {source }}}
$$

Substituting Eq. (15) into Eq. (14) allows the COP to be determined from the exergetic efficiency:

$$
\mathrm{COP}=\left(1-\frac{\bar{T}_{\text {source }}}{T_{0}}\left(\frac{1}{\varepsilon_{\mathrm{HP}}}\left(\frac{T_{0}}{\bar{T}_{\text {sink }}}-1\right)+1\right)\right)^{-1}
$$


The temperature after the mixing point situated between the two HPs, $T_{\mathrm{DH}, 4}$, was determined from a steady state energy balance. As the specific heat was assumed constant and the mass flow ratio, $f_{m}$, was defined, $T_{\mathrm{DH}, 4}$ was found as seen in Eq. (17).

$$
T_{\mathrm{DH}, 4}=f_{m} T_{\mathrm{DH}, 3}+\left(1-f_{m}\right) T_{\mathrm{DH}, 7}
$$

For the purpose of evaluating the exergetic performance of the mixing point the process was evaluated as a cocurrent heat exchanger with no temperature difference at the outlet. The sign of the difference between $T_{\mathrm{DH}, 3}$ and $T_{\mathrm{DH}, 7}$ depends on the value of $f_{Q}$ and $f_{m}$ and thus which stream is the exergetic fuel and which is exergetic product changes accordingly. The exergetic efficiency of the mixing was calculated by either Eq. (18) or Eq. (19) according to the temperature levels of the incoming streams.

$$
\begin{aligned}
& \text { if : } \quad T_{\mathrm{DH}, 3}>T_{\mathrm{DH}, 7}: \quad \varepsilon_{\mathrm{MX}}=\frac{1-f_{m}}{f_{m}} \frac{\left(T_{\mathrm{DH}, 4}-T_{\mathrm{DH}, 7}\right)-T_{0} \ln \left(\frac{T_{\mathrm{DH}, 4}}{T_{\mathrm{DH}, 7}}\right)}{\left(T_{\mathrm{DH}, 3}-T_{\mathrm{DH}, 4}\right)-T_{0} \ln \left(\frac{T_{\mathrm{DH}, 3}}{T_{\mathrm{DH}, 4}}\right)} \\
& \text { if : } \quad T_{\mathrm{DH}, 3}<T_{\mathrm{DH}, 7}: \quad \varepsilon_{\mathrm{MX}}=\frac{f_{m}}{1-f_{m}} \frac{\left(T_{\mathrm{DH}, 4}-T_{\mathrm{DH}, 3}\right)-T_{0} \ln \left(\frac{T_{\mathrm{DH}, 4}}{T_{\mathrm{DH}, 3}}\right)}{\left(T_{\mathrm{DH}, 7}-T_{\mathrm{DH}, 4}\right)-T_{0} \ln \left(\frac{T_{\mathrm{DH}, 7}}{T_{\mathrm{DH}, 4}}\right)}
\end{aligned}
$$

The exergetic efficiency of the total installation was calculated as seen in Eq. (20). Here the entire heat load supplied to the DH stream was accounted as the exergetic product, while the entire heat load supplied from the GT stream plus the power supplied to the two HPs was accounted as the exergetic fuel.

$$
\varepsilon_{\mathrm{tot}}=\frac{\dot{m}_{\mathrm{DH}, 1} c_{p}\left(T_{\mathrm{DH}, 5}-T_{\mathrm{DH}, 1}\right)-T_{0} \dot{m}_{\mathrm{DH}, 1} c_{p} \ln \left(\frac{T_{\mathrm{DH}, 5}}{T_{\mathrm{DH}, 1}}\right)}{\dot{m}_{\mathrm{GT}, 1} c_{p}\left(T_{\mathrm{GT}, 1}-T_{\mathrm{GT}, 4}\right)-T_{0} \dot{m}_{\mathrm{GT}, 1} c_{p} \ln \left(\frac{T_{\mathrm{GT}, 1}}{T_{\mathrm{GT}, \mathrm{out}}}\right)+\dot{W}_{\mathrm{HP}, 1}+\dot{W}_{\mathrm{HP}, 2}}
$$

\subsection{Hybrid absorption-compression heat pump}

The general layout of the investigated HACHP may be seen in Fig. 4 (a). In the desorber heat is supplied from the heat source in order to desorb the ammonia from the rich mixture. The phase change in the desorber is incomplete and thus the stream exiting the desorber is a liquid/vapour mixture. By separating the phases in a liquid-vapour separator (LVS), it can be ensured that only the vapour phase enters the compressor, while the liquid phase is supplied to the pump. The liquid is preheated in the internal HEX, whereafter it is mixed with the vapour stream exiting the compressor. This causes an adiabatic absorption of the vapour phase into the liquid until thermodynamic equilibrium is reached. In the absorber a diabatic absorption process of the ammonia vapour into the liquid takes place while releasing heat to the sink. The exiting stream is a saturated liquid mixture, which is used as the heat source in the internal HEX. The sub-cooled liquid mixture is throttled to the low pressure resulting in a two-phase stream that enters the desorber.

The process described above is sketched in the temperature - heat load diagram shown in Fig. 4 (b). Here the temperature lift, $\Delta T_{\text {lift }}$, is defined as the difference between the sink outlet temperature (heat supply temperature) and the source inlet temperature. The temperature difference, $\Delta T$, is defined as the temperature difference between the inlet and outlet of the sink and source, respectively.

As seen in Fig. 4 (b), temperature and enthalpy are not proportional under the absorption and desorption processes. In Fig. 4 (b) these are depicted as convex profiles but depending on ammonia mass fraction and circulation ratio these profiles may be concave or have both a concave and a convex part, as described in detail by Zheng et al [26]. Given the non-linearity of the temperature profiles, the minimum temperature difference (pinch point temperature difference) cannot be determined uniquely from the inlet and outlet conditions [27]. Hence, additional measures must be applied to ensure the heat transfer processes in the absorber and desorber respect the Second Law of thermodynamics. 
The design of the HACHP is governed by two extra degrees of freedom compared to a conventional VCHP. These can be expressed by the choice of the rich ammonia mass fraction, $x_{r}$, and the choice of the liquid circulation ratio, $f$. The liquid circulation ratio was defined as the ratio between the mass flow rates of the lean and rich solution, see Fig. 4.

As shown in both [22] and [19] the choice of $x_{r}$ and $f$ affect both the system performance (COP) and the system investment. The optimum values of $x_{r}$ and $f$ depend on the HP operating conditions such as sink/source temperature differences as well as the temperature lift [22]. Further, $x_{r}$ and $f$ influence the technical constraints such as high pressure, $p_{H}$, and compressor discharge temperature, $T_{H}$. Thus, it is import to determine the correct combination of $x_{r}$ and $f$ in order to design an economically viable as well technically feasible heat pump solution.

The thermodynamic, heat transfer and economic models of the HACHP were implemented in Engineering Equation Solver (EES) [28] and follows the procedure presented in Jensen et al. [22]. The inputs to the thermodynamic model may be seen in Table 2 .

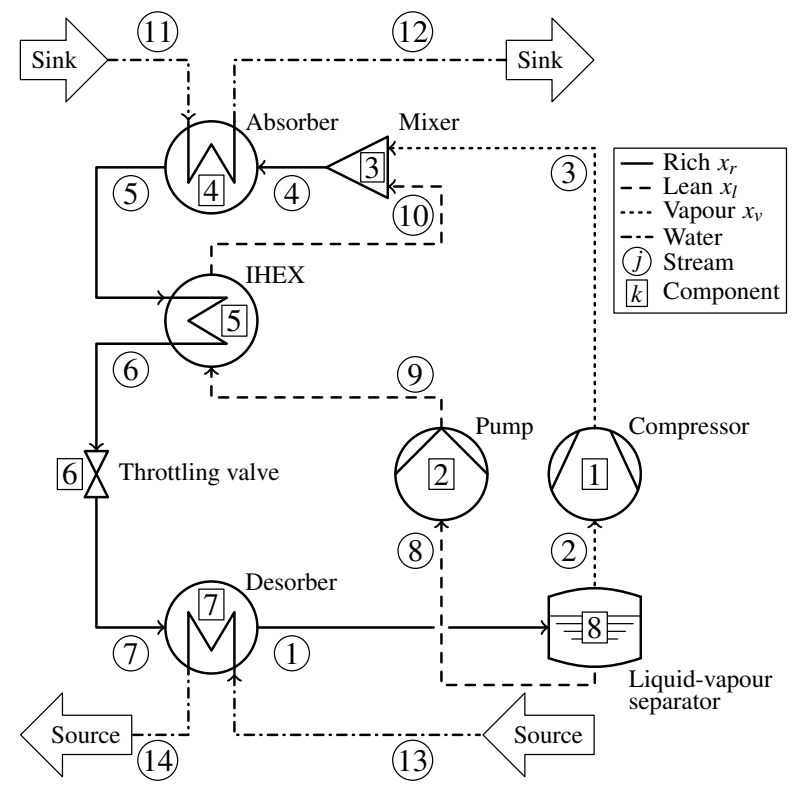

(a)

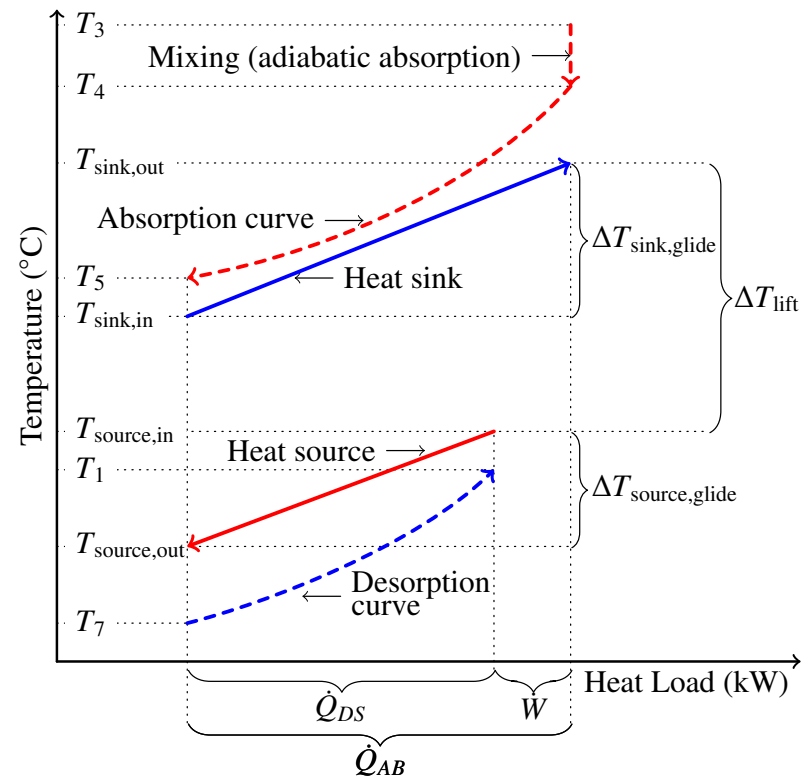

(b)

Figure 4: (a) Principle sketch and (b) Temperature heat load diagram of HACHP

Table 2: Inputs to the thermodynamic model of the HACHP as well as the technical constraints imposed to ensure the applicability of commercial components.

\begin{tabular}{llllll}
\hline \multicolumn{2}{c}{ Thermodynamic model inputs } & \multicolumn{3}{c}{ Technical constraints } \\
\hline$\eta_{\text {is }}$ & Compressor & $0.80-$ & Low pressure $\mathrm{NH}_{3}$ comp. & $p_{H, \max }$ & 28 bar \\
$\eta_{\text {is }}$ & Pump & $0.80-$ & High pressure $\mathrm{NH}_{3}$ comp. & $p_{H, \max }$ & 50 bar \\
$\eta_{\text {elec }}$ & Electric motor efficiency & $0.90-$ & Compressor discharge temp. & $T_{H, \max }$ & $180{ }^{\circ} \mathrm{C}$ \\
$\Delta T_{\mathrm{pp}}$ & Absorber and desorber & $5.0 \mathrm{~K}$ & & & \\
$\epsilon$ & Internal HEX & $0.9-$ & & & \\
\hline
\end{tabular}

\section{Results}

The analysis was divided into three subsections, based on the level of detail of the performance evaluation for the individual heat pumps. The results are presented in terms of key operation criteria for the individual HP units heat load and flow configuration according to Eqs. (2) and (3). 
- As an initial investigation, basic assumptions regarding the exergetic efficiency of the individual units were applied to understand the influence of design parameters on the system exergetic efficiency. The results predict thermodynamic performance improvements for utilising certain configurations, compared to a simple system with only one HP and direct heat exchange.

- The use of a detailed thermodynamic model of the HACHP to predict the performance of the total installation. The results represent detailed information of both HPs and the direct HEX in a specific configuration. The performance improvement, as well as the method to obtain such improvement, was confirmed and refined.

- The use of technical and economic considerations for best possible integration of two HACHPs in a range of exergy-optimal configurations. This was done to analyse the influence of total capital investments, exergetic performance and technical constraints to achieve the minimum PV of a feasible plant.

\subsection{Influence of design parameters on the system exergetic efficiency}

\subsubsection{Heat pumps with equal efficiency $\varepsilon_{\mathrm{HP}, 1}=\varepsilon_{\mathrm{HP}, 2}$}

For the case of equal exergetic efficiency in both HPs, an examination was performed to establish the optimal heat duty of each individual unit (HP 1, HP 2, Direct HEX) according to the principle diagram seen in Fig. 2. If operated without the direct $\operatorname{HEX}\left(f_{Q}=0\right)$, two heat pumps in series with fixed and equal exergetic efficiency will perform with a similar merit as one HP with the same efficiency. In such a case, the full flow of the DH passes through both HPs in succession. With increasing mass flow through the direct HEX, the heat load for the two heat pumps is decreased, but for many flow configurations this additionally leads to increased irreversibilites related to the mixing of the stream from HP 1 and the direct HEX.

The performed analysis for the configuration possibilities of $f_{Q}$ and $f_{m}$ is presented in Fig. 5 for HPs with equal exergetic efficiencies of 0.5 and a direct HEX pinch point temperature difference of $5 \mathrm{~K}$. Fig. 5a shows the influence on the total exergetic efficiency of the system while Figs. $5 b$ and $5 c$ shows the influence directly on the component exergetic efficiency for the HEX and mixing point, respectively.

It is shown, that an optimum system exergetic efficiency exists in the region with a close to even heat distribution between the two HPs $\left(f_{Q, \text { opt }} \approx 0.35\right)$ and close to even mass flow of DH stream in the direct HEX and HP $1\left(f_{m, \text { opt }} \approx\right.$ $0.5)$. At the optimum, the increase in exergetic efficiency of the total installation is approximately $10 \%$ compared to operating a single $\mathrm{HP}$ at an exergetic efficiency of $0.5\left(f_{m}=1\right)$. On the other hand, a reduction of the performance by up to $30 \%$ can be encountered at unfavourable combinations of heat load and mass flow ratios.

Comparing the results presented in Fig. 5a, to the component exergetic efficiencies for the HEX and mixer seen in Figs. 5b and 5c, it is clear that the optimum system exergetic efficiency occurs when the optimum efficiency is attained simultaneously in the HEX and mixer. It is seen from Fig. 5b that the HEX exergetic efficiency peaks at approximately $90 \%$. Further, it may be seen that the heat load ratio has almost no influence on the optimum mass flow ratio. The optimum exergetic efficiency of the HEX occurs when the flows in the HEX are balanced and thus when the DH and GT streams attain the same capacity rates. It may be seen that the exergetic efficiency of the HEX is reduced to a minimum of $78 \%$ as the mass flow ratio approaches unity.

As shown in Fig. 5c, the exergetic efficiency of the mixer peaks at a value of $100 \%$ which can be achieved only when the temperature of the entering streams attain the same value. It may be seen that the point at which this occurs depends on both the heat load and mass flow ratio. Thus, for a given value of $f_{m}$ one value of $f_{Q}$ optimizes the efficiency of the mixer. The efficiency of the mixer may be reduced to a value of $60 \%$ at unfavourable combinations of heat load and mass flow ratios.

From Fig. 5 it can be concluded that the optimal solution is a configuration with a balanced HEX, i.e. similar temperature differences at the inlet and outlet of the HEX, and lowest possible temperature difference between the two streams before mixing.

The benefit of optimal flow and heat load ratio was further found to be dependent on the performance of the direct HEX and the performance of the HPs. In Fig 6 various curves are presented for the optimal configurations for a range of exergetic efficiencies of the HPs and various possible pinch point temperature differences in the direct HEX.

From Fig 6a, it is seen that the overall system efficiency, $\varepsilon_{\text {tot }}$, is greatly influenced by the heat pump exergetic efficiency. However, the system performance can be improved by utilising two HPs and a direct HEX. As seen the improvements of the system when utilising a perfect $\operatorname{HEX}\left(\Delta T_{\mathrm{pp}, \mathrm{HEX}}=0 \mathrm{~K}\right)$ was found to be between 5 and 9 
percentage points when varying the heat pump exergetic efficiency between 0.3 and 0.7 . As seen the improvement compared to the performance of the HP unit decreases as $\Delta T_{\mathrm{pp}, \mathrm{HEX}}$ is increased. Thus, when the direct HEX is not applied the system efficiency assumes the same value as the efficiency of the HP units.

The optimal values of $f_{Q}$ and $f_{m}$ were determined for the considered range of HP exergetic efficiencies. The resulting optimum load share and mass flow ratios are presented in Fig. $6 \mathrm{~b}$ and $6 \mathrm{c}$. The optimum was found for all cases to be the solution with a balanced heat exchanger and equal temperatures prior to mixing. The thermal load of the direct HEX determines the optimal mixing temperature and the load of HP 1 satisfies the required heating of the remaining mass flow, to minimise the losses from mixing.

With smaller pinch point temperature differences, more heat was transferred using the direct HEX, which allowed for higher loads on HP 1, as seen in Fig. 6b. The highest load on HP 1 was determined to be approximately $f_{Q}=0.5$, but in reality the optimal heat load for this unit is lower due to the practical limitations in heat exchange. For the cases with poor pinch point characteristics in the direct HEX, the load of HP 1 was found to be as low as $5 \%$.

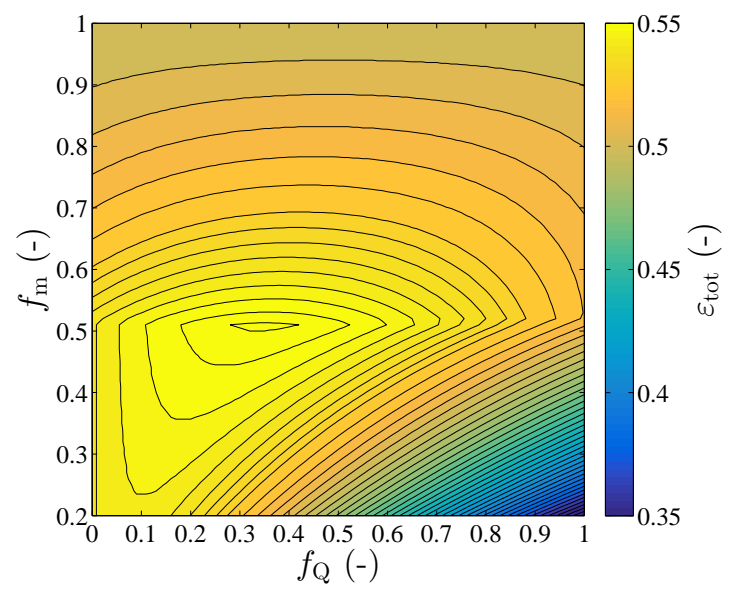

(a)

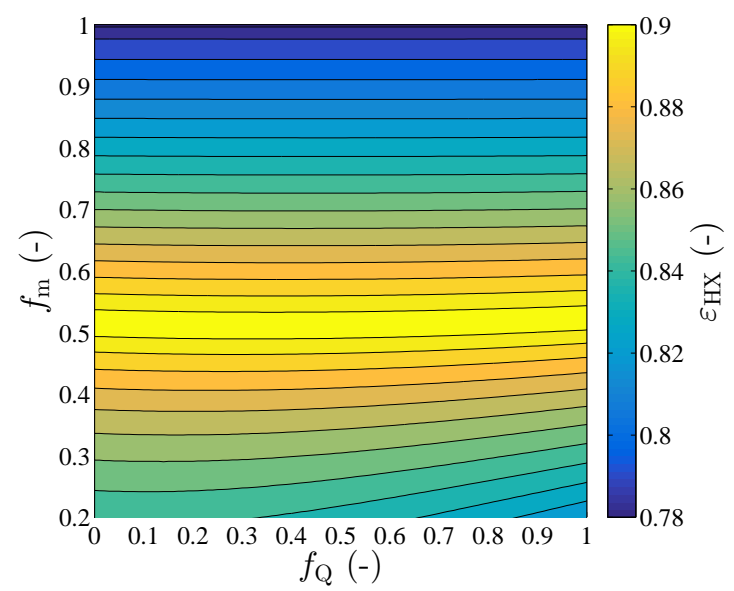

(b)

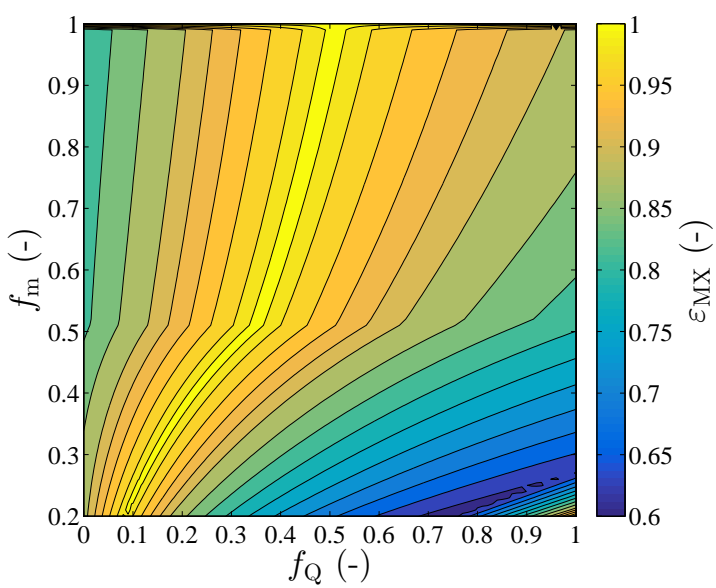

(c)

Figure 5: Performance of the proposed counter current configuration with two HPs with equal exergetic efficiency and a direct HEX with a pinch temperature difference of $5 \mathrm{~K}$. (a) System exergetic efficiency. (b) HEX exergetic efficiency. (C) Mixer exergetic efficiency. 


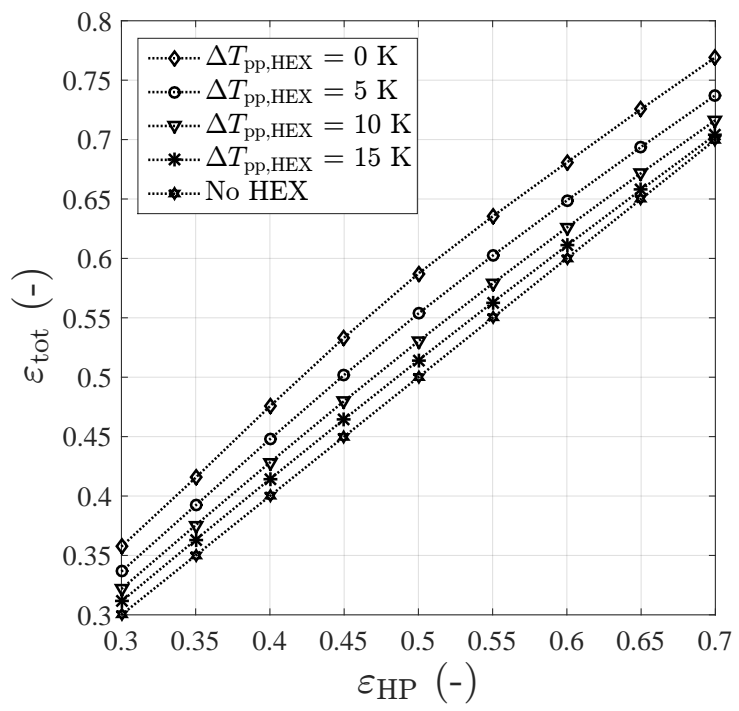

(a)

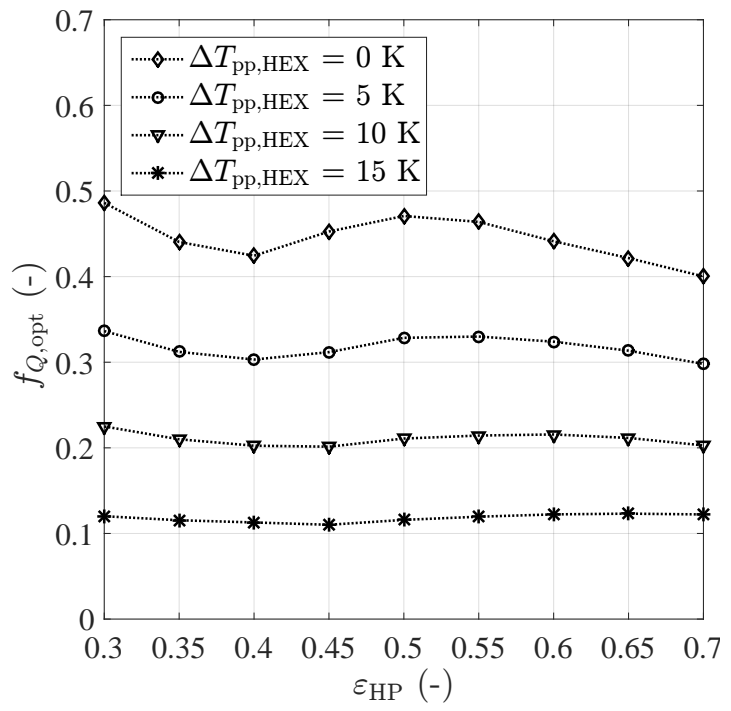

(b)

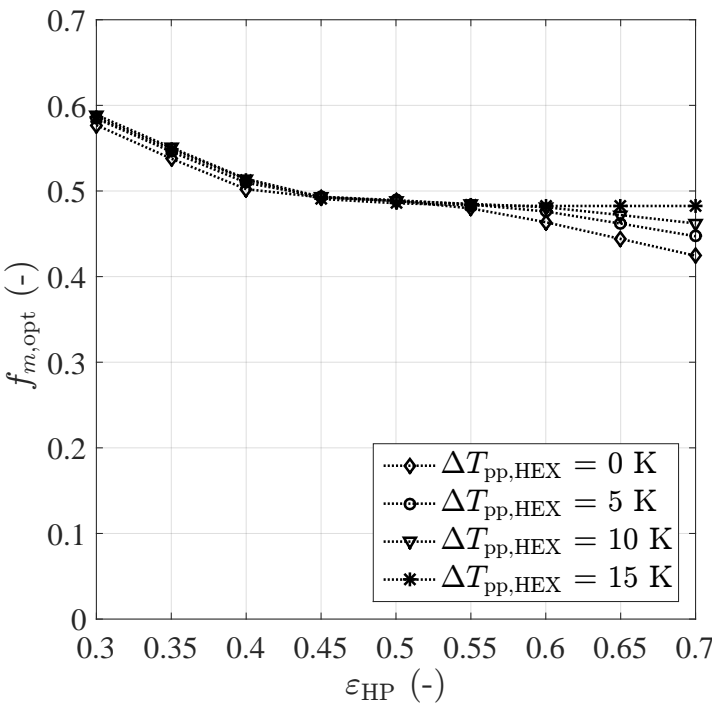

(c)

Figure 6: Influence of HP exergetic efficiency and direct HEX pinch point temperature difference on the performance of the proposed counter current configuration with two HPs of equal exergetic efficiency. (a) Variation of optimum system exergetic efficiency. (b) Variation of optimum heat load ratio. (c) Variation of optimum mass flow ratio. 


\subsubsection{Heat pumps with unequal efficiency $\varepsilon_{\mathrm{HP}, 1} \neq \varepsilon_{\mathrm{HP}, 2}$}

The specific performance of a HP unit in terms of exergetic efficiency can be considered a function of several independent factors, for example both the temperature levels and temperature difference of the sink and source streams can be considered important [21;22]. Other factors include cycle configurations and the type and composition of the working fluid. For the configuration investigated here, variation of the factors $f_{m}$ and $f_{Q}$ will imply significant changes to the operating conditions for each HP unit, and thus the exergetic efficiency of the HPs cannot necessarily be assumed fixed nor equal for the two units.

Thus, in a real case, the preferred configuration differs from the above, as the system benefits from utilising the HP with the highest exergetic efficiency. However, by utilising the high exergetic efficiency of a balanced direct HEX for a fraction of the heat load, a limited reduction in exergetic efficiency for one HP was found to be beneficial depending on the performance of the direct HEX. For the case of a direct HEX with a pinch point temperature difference of 5 $\mathrm{K}$, the optimal configuration is presented in Fig. 7a. The figure reveals two large areas where only the HP with the highest exergetic efficiency should be utilised. The span where two HPs should be utilised is wider at high exergetic efficiencies than at lower efficiencies. The span was found to be slightly slanting, which showed preference for higher loads for HP 2 than for HP 1 . The slanting is a result of the evaluated temperature levels, which for HP 2 allows direct heat exchange between source and sink. In the case where HP 2 operates with an efficiency of 0.5 , the system benefits from utilising a second HP if the unit can operate with an efficiency between 0.45 and 0.5. Oppositely, in the case where HP 1 operates with an efficiency of 0.5 , the use of both heat pumps was beneficial for HP 1 exergetic efficiency below 0.6, as HP 2 includes the possibility for direct heat exchange. In case the HP 1 efficiency is higher than this level, only HP 1 should be utilised.

For configurations utilising the direct HEX, the pinch point temperature difference has a high influence on the feasible area for utilisation of both HPs. For configurations with poor heat exchanger characteristics, the optimum heat load share was shifted completely to the HP which allowed the highest exergetic efficiency. The span where two HPs should be utilised is shown in Fig. $7 \mathrm{~b}$ for a variation in pinch point temperature difference.

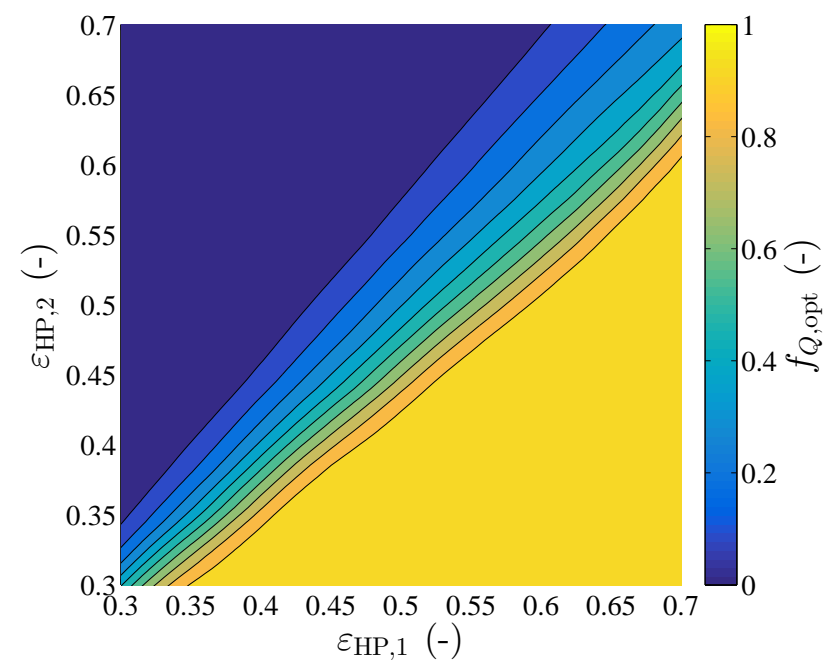

(a)

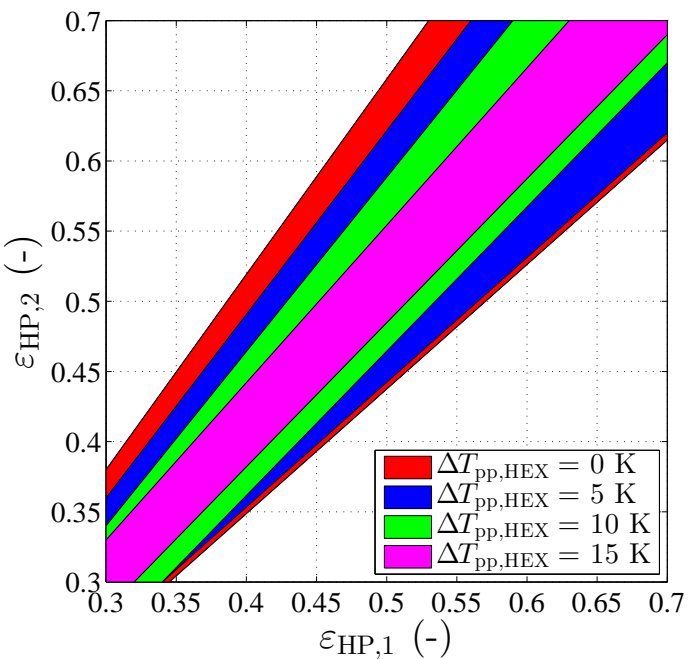

(b)

Figure 7: Performance of the configuration with two HPs with unequal efficiency and a direct $\mathrm{HEX}\left(\Delta T_{\mathrm{pp}, \mathrm{HEX}}=5\right.$ $\mathrm{K})$. (a) Optimal value of $f_{Q}$ as a function of the HP exergetic efficiency. In case of significant differences in the performance of the HPs, the optimal solutions include only one HP. (b) HP exergetic efficiency combinations where two HPs are preferable $\left(0<f_{Q \text {,opt }}<1\right)$ for $\Delta T_{\mathrm{pp}, \mathrm{HEX}}$ from $0 \mathrm{~K}$ to $15 \mathrm{~K}$

\subsection{Hybrid Absorption Compression Heat Pump (HACHP)}

By utilising a model for the specific HP technology, as well as the assumptions of component performance shown in Table 2, the assumed variations in individual HACHP unit exergetic performance reduced to an indication of 
the specific performance (according to the uncertainty of the thermodynamic model). For each of the considered HACHPs, the exergetic performance was optimised in terms of ammonia mass fraction of the individual units, $x_{r}$, and the liquid circulation ratio, $f$.

By calculating the total exergetic efficiency according to the specific operating criteria, a detailed inspection of the thermodynamic optimum was possible. The results of the performed analysis are presented in Fig. 8 for a pinch point temperature difference in the direct HEX of $5 \mathrm{~K}$.

For a pinch point temperature difference in the direct HEX of $5 \mathrm{~K}$, the total exergetic performance of the optimum was found to be approximately 0.64 . The optimum is located at $f_{m}=0.48$ and $f_{Q}=0.39$ at which: $\varepsilon_{\mathrm{HP}, 1}=0.547$ and $\varepsilon_{\mathrm{HP}, 2}=0.615$. The choice of $f_{m}$ corresponds to the specific mass flow required to obtain a balanced direct HEX for the specific temperatures of DH and geothermal source. The contours show, that such mass flow allows higher efficiencies for a wide range of heat load ratios. The optimal heat load ratio corresponds well to the previously established preference for heat load ratios below 0.5 (higher for HP 2 than on HP 1) from Section 3.1.2.

If, for other reasons, only one HP is preferred, the best performance is obtained at $f_{Q}=0$, which restricts utilisation to only HP 2. The optimal exergetic efficiency for such operation was found to be 0.6 , and can be obtained with either a balanced heat exchanger, $f_{m}=0.48$, or an unbalanced heat exchanger, $f_{m}=0$. In case of only one HP without a direct heat exchanger - either $f_{Q}=0$ and $f_{m}=1$ or $f_{Q}=1$ and $f_{m}=1-$ the exergetic efficiency is 0.53 .

\subsection{Technical and economic considerations for best possible integration}

For each of the individual configurations considered in Section 3.2, a set of operating conditions was derived, corresponding to each of the considered HACHP units. Component-specific technical constraints may limit the amount of feasible operating conditions if certain limits are exceeded. For this analysis two specific thermodynamic properties were considered as subject to constraints for feasible operation, according to the presented values of Table 2. High pressure components were identified to a limit of 50 (bar), whereas more conventional components typically operate below a pressure constraints of 28 (bar). Components with high pressure requirements carry along additional investment according to a previous analysis [21;22]. Further, the considered compressors tend to be constrained by high discharge temperatures. For the analysis, the limitation was confined to be below $180{ }^{\circ} \mathrm{C}$, but other suppliers may require further reduction. For the HACHP technology, this technical limit is a significant obstacle in order to achieve high sink temperatures [22]. Based on the derived results of Section 3.2, the relation of optimal mass flow ratio was determined for a range of heat load ratios between 0.2 and 0.6 . The range was chosen as this allows exergetic efficiencies of approximately 0.63 or above. The detailed operation of the two HPs, the direct heat exchanger and the total system is presented in Fig. 9. The heat loads of the individual units are presented in Fig 9a. For all of the optimised systems, the direct heat exchanger was responsible for transferring $1900 \mathrm{~kW}$ of heat. The remaining heat load (approx. $5300 \mathrm{~kW}$ ) was split according to the heat load ratio.

The exergetic efficiencies of the individual units, as well as the total, are presented in Fig. 9b. It is shown, that the exergetic efficiency of the mixer is highest at approximately $f_{Q}=0.35$ - meaning equal temperatures at the outlet both HP 1 and the direct HEX. Above this ratio, the exergy destruction increases significantly as the heated DH stream from HP 1 is mixed with a colder stream from the HEX. However, the exergetic efficiency of both HPs increases with higher heat load ratio, which counterbalances the destruction in the mixer. As noted in Section 3.2, the total exergetic efficiency is optimal at $f_{Q}=0.4$. The variation of the exergetic efficiency of the total system was low, especially for $f_{Q}$ between 0.3 and 0.45 .

The technical parameters were identified for each HACHP based on the results of the investigated systems of Fig. 9. The constrained thermodynamic properties are presented in Fig. 10. The high pressure of the two cycles was well below the upper limit for both cases ( 50 bar), but at a heat load ratio of approximately 0.4 HP 2 changes from low pressure to high pressure components in the high pressure stage. The range of heat load ratios is approximately 0.42 to 0.48 .

The economic performance of the considered span of heat load ratios is presented in Fig. 11. In Fig. 11a the total capital investments (TCI) for each of the units are presented, except for the mixer.

The investment for the direct HEX is quite limited compared to the total, less than $7 \%$ for all cases, even though the required area is high due to the balanced temperature profile. For HP 2 a shift in investment was encountered, when the components are changed for the high-pressure stage according to Fig 10a. It is further shown how the investments for the HPs correspond to the heat load ratio. The total investment cost for the system varies approximately 500.000 EUR, which is up to $18 \%$ increase compared to the lowest possible. 
In terms of present value (PV) of the total investment, the variation of the total system is approximately 650.000 EUR, with the location of the optimum (minimum) at $f_{Q}=0.4$, which was identical with the location of the exergetic optimum. The variation of the PV in the investigated range of $f_{Q}$ is below $5 \%$ compared to the lowest cost.

In Table 3, the characteristics of the chosen operation point are presented. Detailed information on the HPs may be found in Appendix A. The technical constraints in terms of high discharge temperature shifted the chosen operating point away from the economic and exergetic optimum, as lower discharge temperatures are found for heat load ratios higher than 0.42 . The chosen operating point represents a HP with exergetic efficiency of 0.63 which was within $2 \%$ of the theoretical economic optimum.

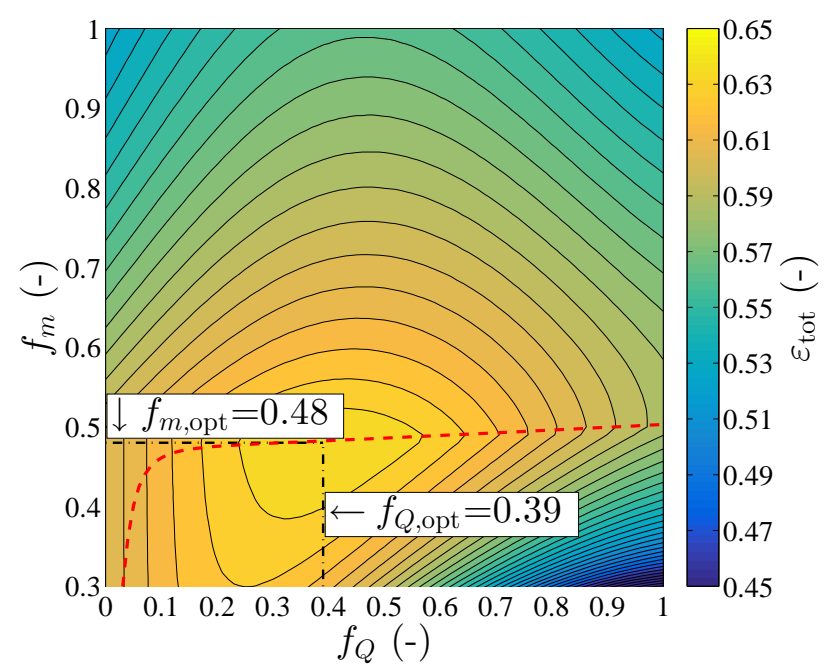

Figure 8: Total exergetic efficiency of configurations with two HACHPs and a direct HEX. For each of the considered HACHPs, the exergetic performance was optimised regarding the ammonia mass fraction of the individual units and the liquid circulation ratio. The pinch temperature difference in the direct HEX was assumed at $5 \mathrm{~K}$. The dashed line presents the optimal $f_{m}$ according to the heat load ratio for achieving the highest exergetic efficiency of the system.

Table 3: System characteristics at the chosen operation point. The optimum in terms of PV was challenged by the technical constraints, which required $f_{Q}$ higher than 0.42 .

\begin{tabular}{llllll}
\hline & Heat Pump 1 & & Heat Pump 2 & \multicolumn{2}{c}{ Heat exchanger } \\
\hline$x_{r}$ & $0.689-$ & $x_{r}$ & $0.772-$ & $\dot{Q}_{\mathrm{HEX}}$ & $1904 \mathrm{~kW}$ \\
$f$ & $0.637-$ & $f$ & $0.493-$ & $\varepsilon_{\mathrm{HEX}}$ & $0.912-$ \\
$p_{H}$ & $16.4 \mathrm{bar}$ & $p_{H}$ & $28.9 \mathrm{bar}$ & TCI & $203,430 \mathrm{EUR}$ \\
$T_{H}$ & $174{ }^{\circ} \mathrm{C}$ & $T_{H}$ & $176^{\circ} \mathrm{C}$ & & \\
$\dot{Q}_{\text {sink }}$ & $2225 \mathrm{~kW}$ & $\dot{Q}_{\text {sink }}$ & $3071 \mathrm{~kW}$ & & \\
$\mathrm{COP}$ & $4.36-$ & $\mathrm{COP}$ & $4.58-$ & & \\
$\varepsilon_{\mathrm{HP}}$ & $0.544-$ & $\varepsilon_{\mathrm{HP}}$ & 0.613 & & \\
TCI & $1,466,225 \mathrm{EUR}$ & $\mathrm{TCI}$ & $1,439,220 \mathrm{EUR}$ & \\
\hline Total system & & & & \\
\hline$\varepsilon_{\mathrm{HP}}$ & $0.634-$ & & \\
TCI & $3,108,875$ EUR & & \\
PV & $15,430,000 \mathrm{EUR}$ & &
\end{tabular}




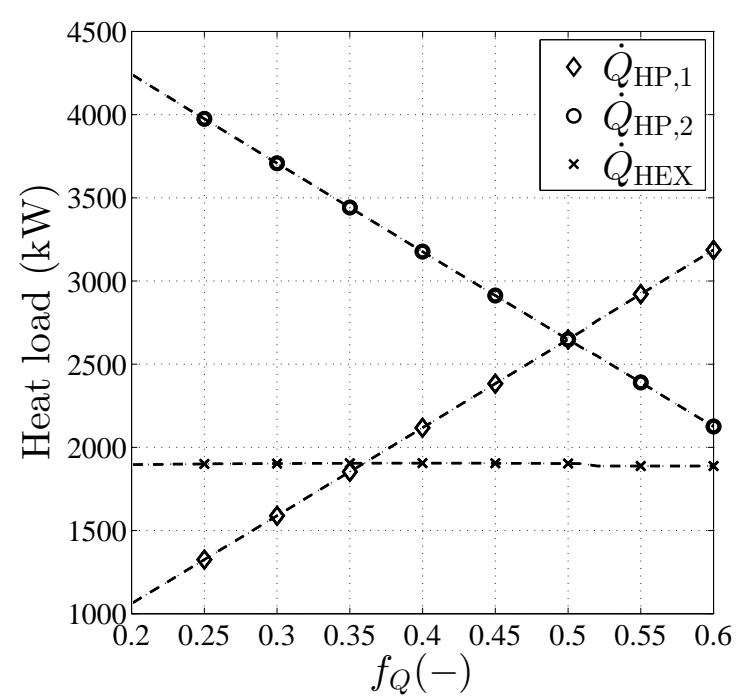

(a)

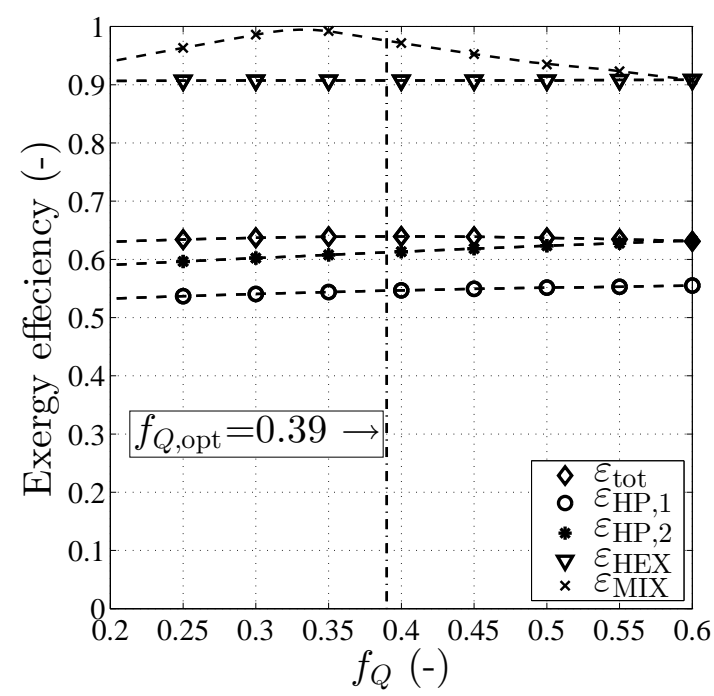

(b)

Figure 9: Operation of the two HACHPs for a range of load ratio configurations with optimal mass flow ratio to achieve best exergetic efficiency. (a) Individual unit load (b) Individual and total exergetic efficiency.

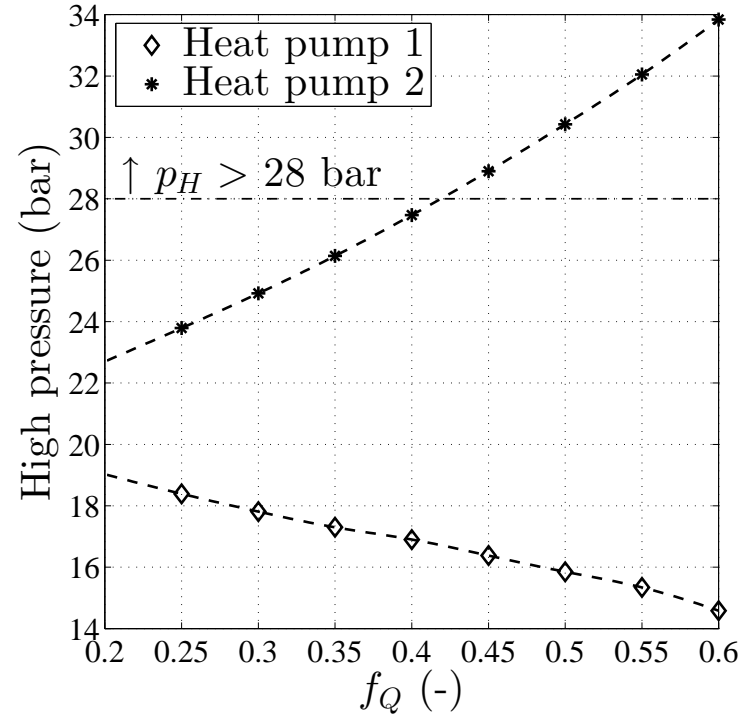

(a)

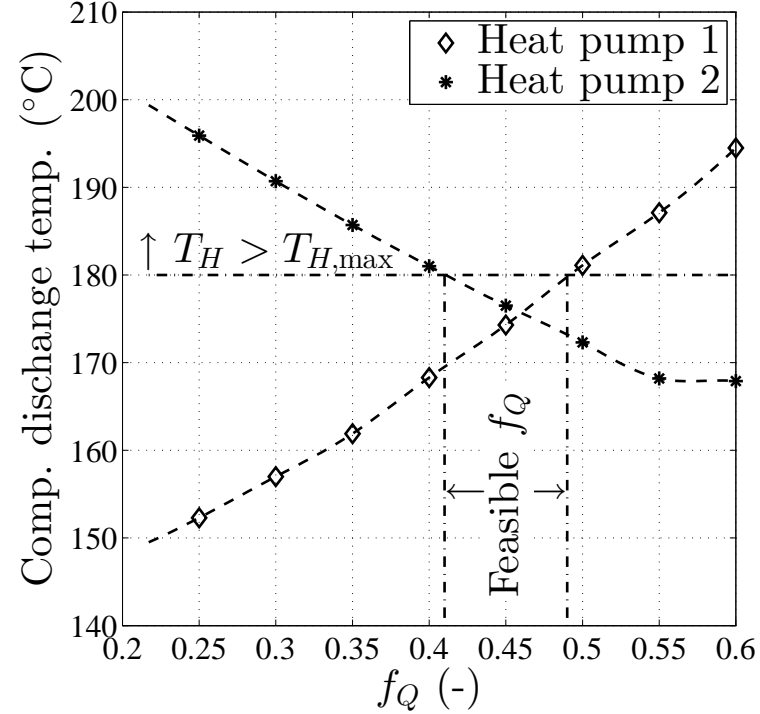

(b)

Figure 10: Technical constraints of the two HACHPs for a range of load ratio configurations with optimal mass flow ratio to achieve best exergetic efficiency. (a) High pressure of HP1 and HP2 (b) Compressor discharge temperature of HP 1 and HP 2. 


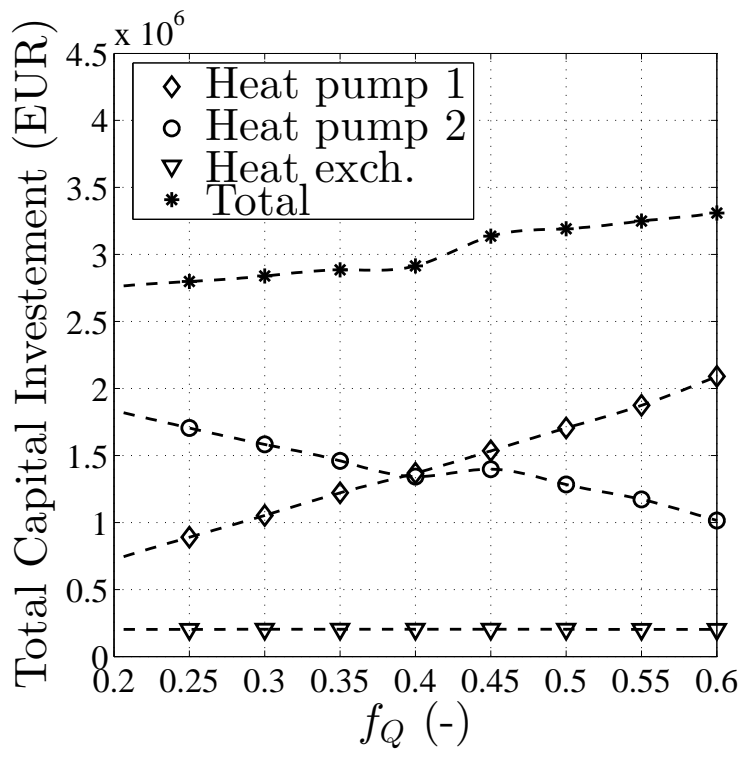

(a)

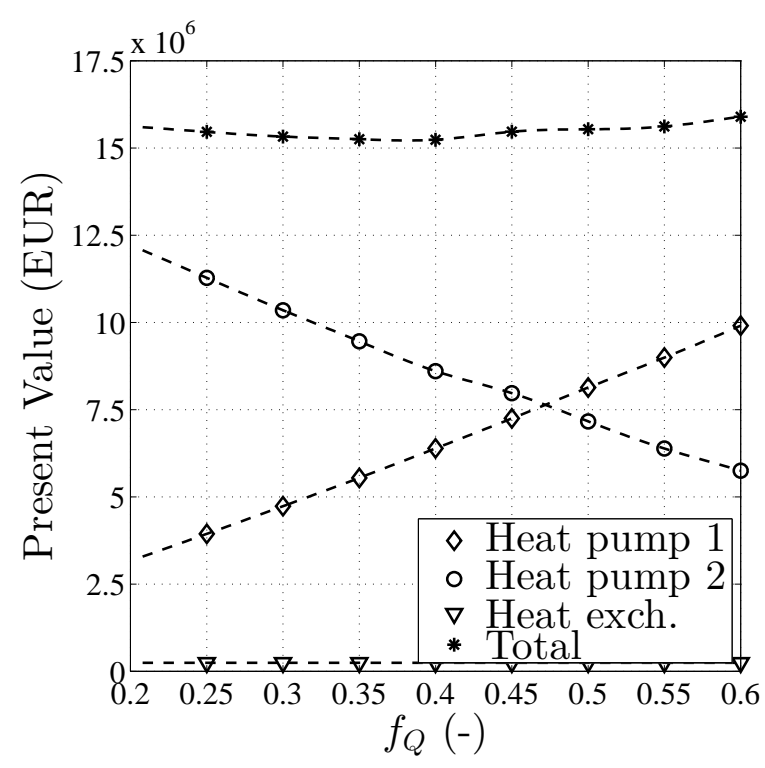

(b)

Figure 11: Economic performance of the two HACHPs for a range of load ratio configurations with optimal mass flow ratio to achieve best exergetic efficiency

\section{Discussion}

The analysis followed a three step increase in the level of detail of the performance evaluation for the investigated HPs. For all three investigations, the results showed a performance gain for utilising a balanced heat exchanger alongside two heat pumps in series. The initial analysis showed that a maximal improvement of 9 percentage points in terms of exergetic efficiency was possible from optimal implementation of the direct HEX, but at the same time, that the highest heat share should be placed on the HP with the best figure of merit. When using detailed models to predict the performance of the HACHP, the real performance improvement from optimal integration was shown to be 0.04. In terms of economy, the minimal PV was found for the same flow configuration.

Due to technical constraints, specifically the high discharge temperature of the compressors, a feasible configuration was proposed, although with slightly higher investment costs. The chosen operating point represents a HP with exergetic efficiency of 0.63 which was within $2 \%$ of the theoretical economic optimum. It should however be expected that the uncertainties of model input, such as e.g. design criteria, component and fuel costs, as well as mathematical representation of the individual components, may offset the theoretical economic optimum.

In the cases where VCHPs were used for the analysis, the system would likely be subject to lower exergetic efficiencies for each HP, due to isothermal phase change characteristics in the heat exchangers. The performance improvement from optimal implementation of the direct HEX would be similar. A feasible method to avoid excess entropy generation from VCHPs in processes with high temperature difference are to increase the number of serially connected HPs, but with the drawback of increased investment due to the economy of scale, which would demand a recalculation of the technical and economically optimal configuration.

\section{Conclusion}

The design of a serially connected ammonia-water hybrid absorption-compression heat pump was investigated for operation in the Greater Copenhagen DH network, in order to supply 7.2 MW heat utilizing a geothermal heat source at $73{ }^{\circ} \mathrm{C}$. Both the heat source and heat sink will experience a large temperature change over the heat transfer process, of which a significant part can be achieved by direct heat exchange. The investigated heat pump configuration may increase the performance due to the non-isothermal phase change. The benefit was further assisted by the use of HPs 
in series. The analysis was divided into three subsections, based on the level of detail of the performance evaluation for the individual heat pumps. The results were presented in terms of key operation criteria for the heat load and flow configuration of the individual HP units. Detailed thermodynamic models predicted that an exergetic efficiency of 0.5 (-) to 0.65 (-) was possible. The technical feasibility as well as the economic viability of this installation was investigated for a range of preferred solutions. The chosen operating point represents a HP with exergetic efficiency of 0.63 (-) which was within $2 \%$ of the theoretical economic optimum.

\section{Acknowledgements}

This research project is financially funded by EUDP (Energy Technology Development and Demonstration). Project title: "Experimental development of electric heat pumps in the Greater Copenhagen DH system - Phase 1", project number: 64014-0127

\section{References}

[1] City Council of Copenhagen . CPH climate plan 2025 (in danish: KBH 2025 klimaplan - en grøn, smart og CO2-neutral by.). 2013. URL: http://cityclimateleadershipawards.com/copenhagen-cph-climate-plan-2025/; [accessed 25.03.14].

[2] CTR, HOFOR and VEKS. Heat plan greater copenhagen 3 (in danish: Varmeplan hovedstaden 3 ).

[3] Mathiesen BV, Lund H, Connolly D. Limiting biomass consumption for heating in 100\% renewable energy systems. Energy 2012;48(1):1608. doi:10.1016/j.energy.2012.07.063.

[4] Ommen T, Markussen WB, Elmegaard B. Lowering district heating temperatures - Impact to system performance in current and future Danish energy scenarios. Energy 2016;94:273-91. doi:10.1016/j.energy.2015.10.063. 2014. URL: http: //www . varmeplanhovedstaden.dk/publikationer-og-moeder; [accessed 25.03.14].

[5] Bach B, Werling J, Ommen T, Münster M, Morales JM, Elmegaard B. Integration of large-scale heat pumps in the district heating systems of Greater Copenhagen. Energy 2016;107:321-34. doi:10.1016/j.energy.2016.04.029.

[6] Lund JW, Freeston DH. World-wide direct uses of geothermal energy 2000. Geothermics 2001;30(1):29-68. doi:10.1016/S03756505(00)00044-4.

[7] Hepbasli A. A review on energetic, exergetic and exergoeconomic aspects of geothermal district heating systems (GDHSs). Energy Conversion and Management 2010;51(10):2041-61. doi:10.1016/j.enconman.2010.02.038.

[8] Arat H, Arslan O. Exergoeconomic analysis of district heating system boosted by the geothermal heat pump. Energy 2017;119:1159-70. doi:10.1016/j.energy.2016.11.073

[9] Unternährer J, Moret S,Joost S, Maréchal F. Spatial clustering for district heating integration in urban energy systems: Application to geothermal energy. Applied Energy 2017;190:746-63. doi:10.1016/j.apenergy.2016.12.136.

[10] Arat H, Arslan O. Optimization of district heating system aided by geothermal heat pump: A novel multistage with multilevel ANN modelling. Applied Thermal Engineering 2017;111:608-23. doi:10.1016/j.applthermaleng.2016.09.150.

[11] Østergaard PA, Lund H. A renewable energy system in Frederikshavn using low-temperature geothermal energy for district heating. Applied Energy 2011;88(2):479-87. doi:10.1016/j.apenergy.2010.03.018.

[12] Prestmark V, Schultz J. Planning and design of a 15 \{MW\} geothermal heat pump installation in Denmark. In: heat pumps for buildings. 1984, p. 171-87.

[13] Osenbrück A. Verfahren zur Kälteerzeugung bei Absorption- maschinen Deutsche. Deutsche Patentschrift 1895;(840 84).

[14] Lorenz H. Beiträge zur Beurteilung von Kühlmaschinen. Z VDI 1894;38:62-68, 98.

[15] Altenkirch E. Kompressionskältemachine mit lösungskreislauf. Kältetechnik 1950;2(10,11,12):251-259,310.

[16] Berntsson T, Hultén M. The compression / absorption cycle - influence of some major parameters on COP and a comparison with the compression cycle ' compression - absorption. International Journal of Refrigeration 1999;22:91-106.

[17] Berntsson T, Hultén M. The compression / absorption heat pump cycle — conceptual design improvements and comparisons with the compression cycle. International Journal of Refrigeration 2002;25:487-97.

[18] Brunin O, Feidt M, Hivet B. Comparison of the working domains of some compression heat pumps and a compression-absorption heat pump. International Journal of Refrigeration 1997;20(5):308-18.

[19] Jensen JK, Markussen WB, Reinholdt L, Elmegaard B. On the development of high temperature ammonia-water hybrid absorption-compression heat pumps. International Journal of Refrigeration 2015;58:79-89. doi:10.1016/j.ijrefrig.2015.06.006.

[20] Jensen JK, Markussen WB, Reinholdt L, Elmegaard B. Exergoeconomic optimization of an ammonia-water hybrid absorption-compression heat pump for heat supply in a spray-drying facility. International Journal of Energy and Environmental Engineering 2015;6(2):195-211. doi:10.1007/s40095-015-0166-0.

[21] Ommen T, Jensen JK, Markussen WB, Reinholdt L, Elmegaard B. Technical and economic working domains of industrial heat pumps: Part 1 - Single stage vapour compression heat pumps. International Journal of Refrigeration 2015;55:168-82. doi:10.1016/j.ijrefrig.2015.02.012.

[22] Jensen JK, Ommen T, Markussen WB, Reinholdt L, Elmegaard B. Technical and economic working domains of industrial heat pumps: Part 2 - Ammonia-water hybrid absorption-compression heat pumps. International Journal of Refrigeration 2015;55:183-200. doi:10.1016/j.ijrefrig.2015.02.011.

[23] Ommen T, Jensen JK, Markussen WB, Elmegaard B. Enhanced technical and economic working domains of industrial heat pumps operated in series. IIF-IIR; 2015, 
[24] Grüner S, Elmegaard B, Ommen T, Rothuizen ED, Jensen JK, Christensen C, et al. Experimental development of electric heat pumps in the Greater Copenhagen DH system - Phase 1. Tech. Rep.; HOFOR, CTR, VEKS, Innoterm, Alfa Laval, DME, TI, DTU.; Copenhagen; 2016. URL: http: //www.hofor.dk/wp-content/uploads/2016/02/svaf_final-report_2016-02-02.pdf.

[25] Berntsson T. Heat sources - Technology, economy and environment. International Journal of Refrigeration 2002;25(4):428-38. doi:10.1016/S0140-7007(01)00034-2.

[26] Zheng N, Song W, Zhao L. Theoretical and experimental investigations on the changing regularity of the extreme point of the temperature difference between zeotropic mixtures and heat transfer fluid. Energy 2013;55:541-52.

[27] Itard LCM, Machielsen CHM. Considerations when modelling compression/resorption heat pumps. International Journal of Refrigeration 1994;17(7):453-60.

[28] Klein SA. Engineering Equation Solver Academic Professional V9.459-3D. 2013.

\section{Appendix A. Detailed outputs for the best possible design.}

Table A.4: State points for HP 1 under the suggested design conditions

\begin{tabular}{ccccccc}
\hline$\dot{m}_{j}(\mathrm{~kg} / \mathrm{s})$ & $p($ bar $)$ & $T\left({ }^{\circ} \mathrm{C}\right)$ & $s(\mathrm{~kJ} / \mathrm{kg}-\mathrm{K})$ & $h(\mathrm{~kJ} / \mathrm{kg})$ & $x(-)$ & $v\left(\mathrm{~m}^{3} / \mathrm{kg}\right)$ \\
\hline 41.41 & 3.589 & 27.59 & 1.973 & 414.9 & 0.689 & $1.44 \mathrm{E}-01$ \\
1.505 & 3.589 & 27.59 & 4.982 & 1344 & 0.997 & $3.93 \mathrm{E}-01$ \\
1.505 & 16.38 & 174.3 & 5.128 & 1663 & 0.997 & $1.28 \mathrm{E}-01$ \\
4.140 & 16.38 & 81.77 & 2.318 & 611.3 & 0.689 & $3.61 \mathrm{E}-02$ \\
4.140 & 16.38 & 58.53 & 0.752 & 74.13 & 0.689 & $1.41 \mathrm{E}-03$ \\
4.140 & 16.38 & 41.70 & 0.506 & -5.420 & 0.689 & $1.37 \mathrm{E}-03$ \\
4.140 & 3.589 & 11.00 & 0.538 & -5.420 & 0.689 & $4.08 \mathrm{E}-02$ \\
2.635 & 3.589 & 27.59 & 0.255 & -116.0 & 0.513 & $1.22 \mathrm{E}-03$ \\
2.635 & 16.38 & 27.78 & 0.257 & -114.0 & 0.513 & $1.22 \mathrm{E}-03$ \\
2.635 & 16.38 & 55.49 & 0.654 & 10.94 & 0.513 & $1.26 \mathrm{E}-03$ \\
22.04 & 10.00 & 50.00 & 0.703 & 210.2 & - & - \\
22.04 & 10.00 & 74.13 & 1.004 & 311.1 & - & - \\
23.91 & 10.00 & 33.41 & 0.483 & 140.8 & - & - \\
23.91 & 10.00 & 16.00 & 0.239 & 68.05 & - & - \\
\hline
\end{tabular}

Table A.5: State points for HP 2 under the suggested design conditions

\begin{tabular}{ccccccc}
\hline$\dot{m}_{j}(\mathrm{~kg} / \mathrm{s})$ & $p(\mathrm{bar})$ & $T\left({ }^{\circ} \mathrm{C}\right)$ & $s(\mathrm{~kJ} / \mathrm{kg}-\mathrm{K})$ & $h(\mathrm{~kJ} / \mathrm{kg})$ & $x(-)$ & $v\left(\mathrm{~m}^{3} / \mathrm{kg}\right)$ \\
\hline 4.554 & 7.946 & 48.94 & 2.663 & 687.1 & 0.772 & $9.42 \mathrm{E}-02$ \\
2.307 & 7.946 & 48.94 & 4.706 & 1372 & 0.996 & $1.85 \mathrm{E}-01$ \\
2.307 & 28.88 & 176.5 & 4.829 & 1645 & 0.996 & $7.08 \mathrm{E}-02$ \\
4.554 & 28.88 & 104.8 & 2.928 & 881.9 & 0.772 & $2.96 \mathrm{E}-02$ \\
4.554 & 28.88 & 76.11 & 1.061 & 207.5 & 0.772 & $1.56 \mathrm{E}-03$ \\
4.554 & 28.88 & 65.13 & 0.902 & 152.5 & 0.772 & $1.52 \mathrm{E}-03$ \\
4.554 & 7.946 & 28.41 & 0.944 & 152.5 & 0.772 & $2.59 \mathrm{E}-02$ \\
2.247 & 7.946 & 48.94 & 0.566 & -16.52 & 0.542 & $1.27 \mathrm{E}-03$ \\
2.247 & 28.88 & 49.35 & 0.568 & -13.19 & 0.542 & $1.27 \mathrm{E}-03$ \\
2.247 & 28.88 & 73.47 & 0.901 & 98.17 & 0.542 & $1.32 \mathrm{E}-03$ \\
51.77 & 10.00 & 70.84 & 0.965 & 297.3 & - & - \\
51.77 & 10.00 & 85.00 & 1.134 & 356.7 & - & - \\
26.98 & 10.00 & 55.00 & 0.767 & 231.1 & - & - \\
26.98 & 10.00 & 33.41 & 0.483 & 140.8 & - & - \\
\hline
\end{tabular}


Table A.6: Heat transfer area, mean temperature difference and pressure loss for the plate heat exchangers of HP 1 and HP 2 under the suggested design conditions.

\begin{tabular}{ccccll}
\hline & $\dot{Q}(\mathrm{~kW})$ & Area $\left(\mathrm{m}^{2}\right)$ & $\Delta \bar{T}\left({ }^{\circ} \mathrm{C}\right)$ & $\Delta p$ hot side (bar) & $\Delta p$ cold side (bar) \\
\hline Heat Pump 1 & & & & & \\
Absorber & 2225 & 132.5 & 5.939 & $5.50 \mathrm{E}-04$ & $4.95 \mathrm{E}-02$ \\
Desorber & 1740 & 166.3 & 6.543 & $8.19 \mathrm{E}-03$ & $5.81 \mathrm{E}-04$ \\
IHEX & 329.4 & 31.46 & 7.155 & $6.77 \mathrm{E}-03$ & $2.78 \mathrm{E}-03$ \\
Heat Pump 2 & & & & & \\
Absorber & 3072 & 90.30 & 7.227 & $1.51 \mathrm{E}-03$ & $4.98 \mathrm{E}-01$ \\
Desorber & 2435 & 163.7 & 7.733 & $6.59 \mathrm{E}-03$ & $7.23 \mathrm{E}-04$ \\
IHEX & 250.2 & 13.65 & 7.339 & $4.02 \mathrm{E}-02$ & $9.72 \mathrm{E}-03$ \\
\hline
\end{tabular}

